\title{
An Internet for, and from, us all
}

\section{The digital revolution needs to include the voices of marginalized communities, say Anasuya Sengupta, Siko Bouterse and Kira Allmann.}
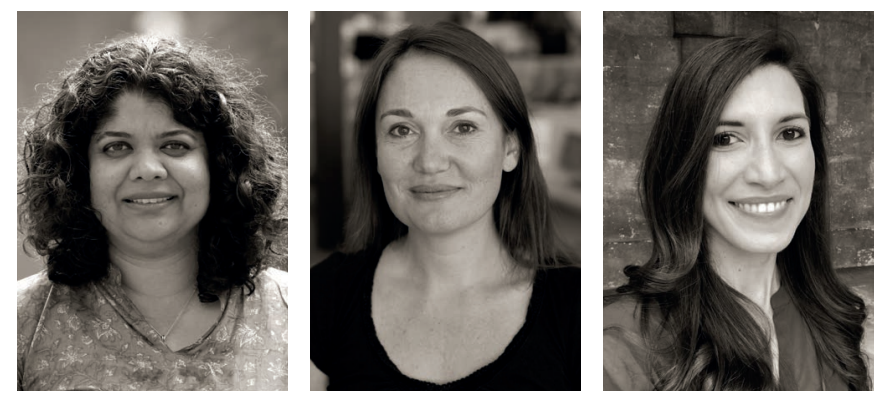

I n 2014, Grace Banu joined Sri Krishna College of Engineering and Technology in Sugunapuram, India, to study electrical engineering. This would be an important achievement for anyone, but Grace's admission was particularly noteworthy.

She comes from the Dalit, a community in India of more than 200 million people that has been shunned for centuries. Formerly and pejoratively known as the 'Untouchables', Dalits have been marginalized. They exist outside India's hierarchical caste system, and have a traditional role as scavengers, cleaning up faeces and removing corpses. Furthermore, Grace is transgender, and until a few months ago, India kept the trans community on the edge of fear and criminalized homosexuality.

Grace overcame these multiple forms of oppression to become the first Dalit transgender person to be admitted to an engineering college in the southern Indian state of Tamil Nadu. She continues to fight for recognition and respect for herself and others today - including online. In 2018, we supported the efforts of the Dalit community to bring Grace's biography to Wikipedia so others might be inspired by her. But establishing her presence - and keeping it there - was almost as much of a challenge as it was for her to become an engineer.

Despite being in the numerical majority, women, people of colour and those born in Asia, Africa, Latin America and the Middle East are marginalized through pre-existing structures of power and privilege. This is true in the physical world, and it is true online. We are the majority of everyday Internet users, but our perspectives and histories are not well represented on the Internet. Technology is often said to be a democratizing force, but those in positions of power and privilege control what knowledge is visible and retained for posterity.

Internet access remains unevenly spread, but it is more ubiquitous than many people realize: $45 \%$ of women in the world are online today, and $74 \%$ of the online population is connecting from outside North America and Europe. But the content published on the Internet is deeply skewed. On Wikipedia - the fifth-most-visited website in the world and a good indicator of the world's online knowledge fewer than one-quarter of all biographies are of women. And although the population of Africa is more than one-and-a-half times greater than that of Europe, only $15 \%$ of the articles available on Wikipedia focus on it. There are more articles written about Antarctica than about many parts of Africa, Latin America and Asia. These biases reflect the make-up of the site's editors: $80 \%$ of Wikipedia is created and maintained by people from North America and Europe - a demographic that accounts for less than $20 \%$ of the world's population. It is estimated that only $10 \%$ of Wikipedia editors identify as female.

Even within North America and Europe, knowledge on platforms such as Wikipedia is narrated from privileged perspectives to the detriment of those from marginalized communities. For many years, the Wikipedia entry for the California Gold Rush - a page viewed by hundreds of thousands of people seeking to understand the event each year - illustrated a section about the impact on Native Americans with an image showing Native Americans violently attacking white settlers (see 'A tale of two images'). At a Wikipedia conference in San Diego, California, in October 2016, Michael Connolly Miskwish, a member of the Campo Kumeyaay Nation, spoke of the need to remember the systematic genocide of Native Americans that took place at the time. During the conference, a group of Wikipedians worked with Miskwish to change the image. It now depicts white settlers' aggression towards Native Americans - a more realistic picture of events.

This work to challenge gaps in knowledge and to better represent the perspectives and experiences of marginalized communities online is crucial and urgent, and people all over the world are taking up the fight. Our multilingual global campaign, 'Whose Knowledge?', is part of an effort involving many groups and communities that are working to build a more equitable Internet. But there are many challenges ahead, and if the Internet is to reflect the plurality, depth and breadth of human knowledge, we need significant support in several key areas.

\section{Expand non-textual knowledge online.}

The huge gaps in the world's recorded knowledge can be filled by curating and sharing oral, visual and other non-textual knowledge. Community-led oral archives are already bringing new voices online. For example, the Kvir Arhiv website documents, in their own words, the experiences of activists from the queer community of Bosnia-Herzegovina during the Bosnian War in the 1990s. And the People's Archive of Rural India is the first online repository of visual, oral and textual material on the diverse range of communities and languages that represent rural India.

Researchers, archivists and librarians, in particular, should seek to form partnerships with community organizers to preserve and amplify knowledge in multiple forms beyond the written word. To succeed, these initiatives must be driven by the priorities of the marginalized communities whose knowledge is being shared.

Improve tools for the preservation and expansion of language. Language is one of the best proxies for culture and knowledge, and 


\section{A TALE OF TWO IMAGES}

For many years, the Wikipedia entry for the California Gold Rush included an image (A) of Native Americans attacking white settlers that was taken from an 1859 edition of Hutchings' Illustrated California Magazine. Attendees at a 2016 Wikipedia conference replaced it with an image (B) depicting aggression by the settlers that was created by artist John Ross Browne in 1864.
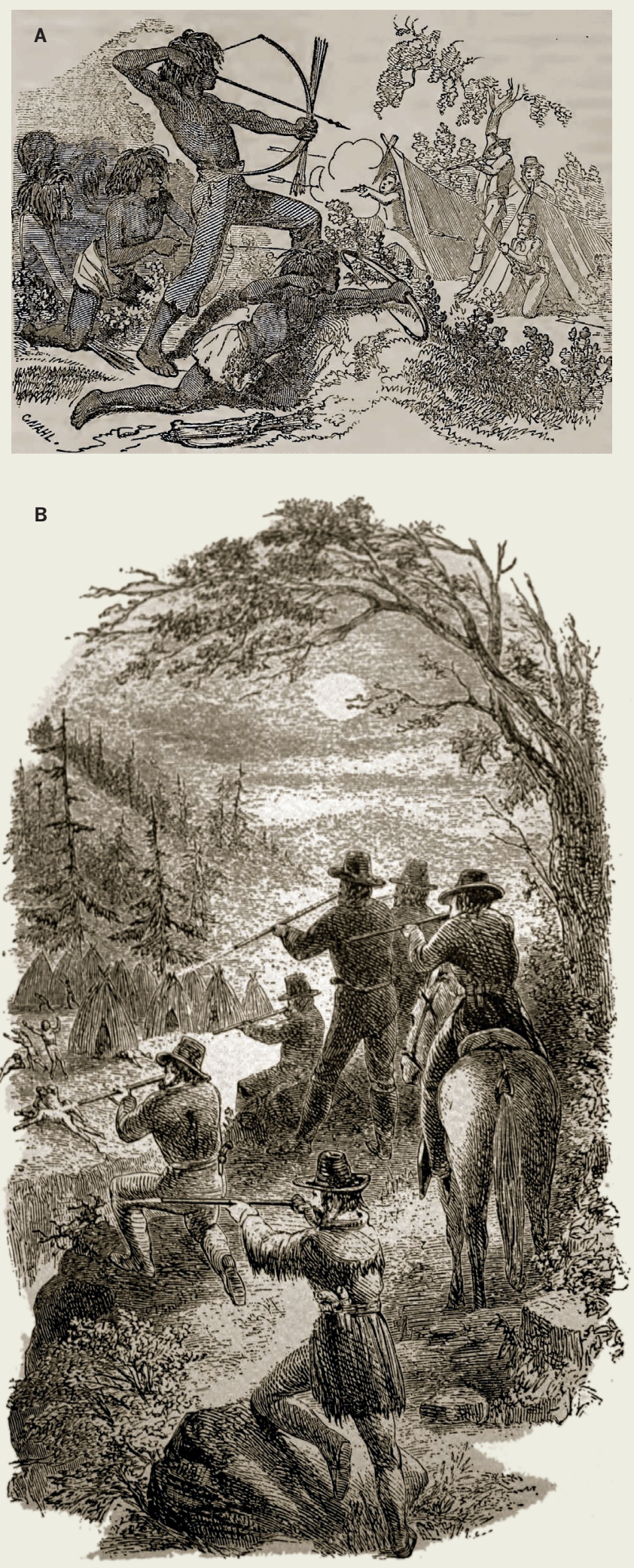

much is lost in translation when we cannot communicate in our own language. And when languages are lost, we also lose other forms of embodied knowledge.

Important efforts are under way to protect the world's linguistic diversity. The Endangered Languages Documentation Programme at the School of Oriental and African Studies in London is creating audio and video recordings of speakers of endangered languages and making them freely available online. And technologists such as those at the $\mathrm{O}$ Foundation are working to build new tools to better translate and display less-widely spoken languages on digital devices. More collaboration of this nature - between technologists, linguists and native-language speakers - is needed to expand access to these languages online in a way that is both useful to, and respectful of, the communities that speak them.

Highlight the contributions of women and other marginalized communities online.

Right now, the lives and deeds of the majority of the world's people are largely missing from the Internet's record of human knowledge. Groups such as Wikimujeres, AfroCROWD, the Black Lunch Table, Art+Feminism, Women in Red, and Dalit History Month are bringing the knowledge of women and other marginalized groups onto Wikipedia by encouraging people to participate in producing and sharing content.

In March 2018, for example, Whose Knowledge? launched a campaign called Visible Wiki Women to make images of women, including scientists and technologists, available to use in articles. These images can be used by Wikipedia editors and community groups to improve existing articles, and to create articles about notable women who previously had no presence on the site.

Whatever our expertise, we need to be more conscious of whose contributions we acknowledge and make visible. Scholars, researchers and publishers, in particular, need to actively support the creation and curation of these missing histories and knowledge bases.

\section{Challenge the status quo of both Internet architecture and its governance.}

If women, people of colour and other marginalized communities lead the design of online platforms and tools, the Internet will be more accessible to all the world's peoples, and will be a richer resource as a result.

However, although the Internet is theoretically international, such choices commonly emanate from the monocultural landscape of Silicon Valley. Information and technology networks such as the Association for Progressive Communications are challenging policymakers to change how decisions around Internet architecture and governance are made, and to allow people everywhere to contribute to the rules and structures of our increasingly interconnected world. Technology companies and states need to recognize the opportunities that diversifying design and governance can offer, and the ethical imperatives that underlie them.

The Internet is claimed to be an emancipatory and democratic space where everyone can participate in the production of knowledge and have their contribution recognized. But it can never fulfil its transformational potential without much greater diversity of content, contributors and forms of knowledge. Achieving this will require everyone's combined efforts. Let's build an Internet that is truly for, and from, us all.

Anasuya Sengupta is a feminist scholar and activist, and co-founder of Whose Knowledge? Siko Bouterse is an online community organizer, and co-founder of Whose Knowledge? Kira Allmann is a media law and policy researcher at the Centre for Socio-Legal Studies at the University of Oxford, UK.

e-mail:info@whoseknowledge.org 